\title{
LA VIOLENCIA DE GÉNERO COMO OPRESIÓN ESTRUCTURAL*
}

\author{
GENDER VIOLENCE AS STRUCTURAL OPPRESSION
}

\author{
Luis Villavicencio Miranda* \\ Alejandra Zúñiga Fajuri ${ }^{* *}$
}

\begin{abstract}
RESUMEN: La violencia y marginación de las mujeres es una realidad transversal, se presenta en todos los países del mundo con independencia de su nivel de desarrollo. Para comprender este fenómeno debemos analizar el modo en que el género opera como una forma de opresión subyacente a la propia estructura de nuestras sociedades, a la forma en que repartimos el poder, organizamos el Estado y por cierto, al modo en que comprendemos el Derecho.
\end{abstract}

Palabras clave: Mujer, marginalidad, violencia, poder.

ABSTRACT: Violence and marginalization of women is a cross-reality, occurs in all countries of the world, including those classified as "developed". To understand this phenomenon we analyze how gender is a form of underlying oppression that influence the way we organize and distribute power and, indeed, the way we understand the law. This paper attempts to make a contribution in this direction.

Key words: Women, marginalization, violence, power.

\section{INTRODUCCIÓN}

Sabemos que las mujeres padecen atroces formas de violencia tales como la ablación o mutilación genital, el planchado de pechos, la lapidación, la violación retributiva, la esclavitud sexual, los matrimonios concertados de niñas o el rapto de novias. Aunque esa violencia afecta a millones de mujeres, no suele ser portada en los periódicos pues se piensa que, afortunadamente, se trata de una realidad que nos es ajena, propia de culturas "no occidentalizadas" en las que los indudables beneficios de una democracia de derechos no han llegado". Pero lo cierto es que en todos los países del mundo, incluidas las "decentes" democracias occidentales modernas, la realidad de las mujeres es muy distinta a la de los hombres.

Las mujeres representan el $70 \%$ de la población mundial viviendo bajo pobreza. Su salario es entre un $10 \%$ y un $30 \%$ menor que el de los varones en el mismo cargo, con las mismas funciones (en algunos países la brecha se sitúa entre el 30 y 40\%). Ellas son responsables de dos tercios del trabajo realizado en el mundo, pero reciben solo el $10 \%$ de los

\footnotetext{
* El presente trabajo forma parte del Proyecto FONDECYT No 1120566 titulado "Ciudadanía para las mujeres en una sociedad multicultural. Hacia la construcción de una concepción deliberativa con vocación universal y su impacto institucional".

** Luis Villavicencio Miranda. Doctor en Derecho. Académico de la Universidad de Valparaíso. Alejandra Zúñiga Fajuri. Doctora en Derecho. Académica de la Universidad de Valparaíso. Dirección postal: Av. Errázuriz No 2120, Valparaíso.Correo electrónico: luis.villavicencio@uv.cl, alejandra.zuniga@uv.cl.

1 Villavicencio(2014).
} 
beneficios. Son propietarias del 1\% de las tierras de cultivo, aunque representan el $80 \%$ de la mano de obra campesina. Por si fuera poco, dos de cada tres (un 66\%) sufre algún tipo de violencia (física, sexual, psicológica o económica) dentro o fuera de sus hogares ${ }^{2}$.

El fenómeno de la violencia contra las mujeres es transversal, o sea, se presenta en todos los países del mundo, incluso en aquellos que se caracterizan por una consolidada práctica de protección y promoción de derechos fundamentales. ¿Por qué sucede este fenómeno? En lo que sigue intentaremos mostrar que la respuesta se encuentra en comprender que la violencia de género -real y simbólica- opera como una forma de opresión subyacente a la propia estructura de nuestras sociedades, a la forma en que organizamos el Estado y, por cierto, al modo en que comprendemos el Derecho.

\section{LO PERSONAL ES POLÍTICO. LA FALSA DICOTOMÍA ENTRE LO PÚBLICO Y LO PRIVADO}

Uno de los aspectos centrales de las teorías de la justicia (especialmente la liberal) es la separación entre la esfera pública y la esfera privada, entre lo político y lo no político ${ }^{3}$. Mediante esa tajante división, se expresa y reproduce una demarcación de los géneros en la que las mujeres se identifican con lo privado - con la naturaleza y la desigualdad- mientras que los varones se identificarían con lo público-político, con la cultura y la igualdad. Ellos se desenvuelven en el espacio en que se los reconocen como ciudadanos iguales, donde el poder es distribuido de forma equitativa. Ellas, en cambio, viven en el espacio privado, donde se les niega el reconocimiento de su individualidad ${ }^{4}$.

La consigna "lo personal es político" ilustra muy bien el carácter ideológico de los supuestos en los que se sustenta la distinción liberal entre lo público y lo privado, tributarios del patriarcado (distribución desigual del poder entre los sexos). Pateman sostiene que dicha consigna "ha llamado la atención de las mujeres sobre la manera en la que se nos insta a contemplar la vida social en términos personales, como si se tratase de una cuestión de capacidad o de suerte individual a la hora de encontrar a un hombre decente con el que casarse o un lugar apropiado en el que vivir. Las feministas han hecho hincapié en cómo las circunstancias personales están estructuradas por factores públicos, por leyes sobre violación (...) y por el estatus de 'esposa', por políticas relativas al cuidado de los niños, por la asignación de subsidios propios del Estado del bienestar y por la división sexual del trabajo en el hogar y fuera de él. Por tanto, los problemas 'personales' solo se pueden resolver a través de medios y de acciones políticas" ${ }^{\text {. }}$.

La compleja posición de las mujeres en las sociedades liberal-patriarcales contemporáneas confirma, en sus experiencias cotidianas, que efectivamente los ámbitos de lo público y lo privado están separados; pero, al mismo tiempo, también ratifica que están conectados y que esa relación debería interesarle a la justicia. Evidentemente, desde los orígenes

\footnotetext{
2 Amnistía Internacional(2009).

3 Villavicencio (2013).

4 Sánchez (2002).

5 Pateman (1996) pp. 46-47.
} 
de la sociedad burguesa liberal, las mujeres nunca fueron totalmente excluidas de la vida pública, aunque el modelo ideal de una mujer decente para todas las clases respetables de la sociedad era la de la esposa-madre económicamente dependiente.

En los tiempos actuales, las mujeres todavía siguen teniendo, en el mejor de los casos, una representación marginal en los cargos de poder relevantes. La realidad expresada por los datos es que los hombres siguen gobernando el mundo ${ }^{6}$. Esto significa que, en lo que respecta a la toma de decisiones que nos afectan a todos, la voz de las mujeres no es escuchada. Las mujeres ejercen menos del 10\% de los cargos de jefes de Estado, ocupan solo el 20\% de los escaños parlamentarios de todo el mundo (Informe parlamentario mundial, 2012). Además, las mujeres integran solo el 5\% de las juntas directivas de las grandes empresas latinoamericanas, mientras que en las grandes empresas europeas solo hay una media de un 3\% de mujeres en puestos directivos, según los datos del 2012, de Catalyst Census: Fortune 500 Women Board Directors.

Aunque un número cada vez más creciente de mujeres se ha incorporado al mundo público del empleo remunerado, sus condiciones en el espacio privado no se han visto mayormente alteradas. Ello solo ratifica la continuidad de un modelo patriarcal basado en la división sexual del trabajo en la familia y en la división sexual de las labores en el ámbito profesional. Muchas investigaciones han probado que las mujeres trabajadoras se concentran en unas pocas áreas ocupacionales (trabajos para mujeres) que son peor remunerados, despreciados, y de baja calificación.

¿Por qué razón si las mujeres se han incorporado, en algunos casos masivamente, al mercado laboral continúan ocupando las peores plazas laborales? La razón parece estar tanto en la práctica como en la teoría. Desde el punto de vista teórico, los debates sobre la vida laboral -desde el neoliberalismo al marxismo- dan siempre por supuesto que es posible comprender la actividad productiva prescindiendo de la vida doméstica. Se omite que el trabajador (idealizado como un hombre) puede estar listo para laborar y para concentrarse en sus obligaciones porque se encuentra liberado de la cotidiana necesidad de preparar comida, lavar, limpiar, y atender a los hijos y ancianos, exclusivamente porque cada una de esas tareas son realizadas gratuitamente por sus parejas. Y si esta es también una persona asalariada, tiene que dedicar una jornada complementaria (la invisible doble jornada) a esas actividades que por "naturaleza" les corresponden. En consecuencia, "solo será posible obtener un análisis y una explicación completa de la estructura y de la forma en la que opera el capitalismo cuando, además de la figura del trabajador, se tenga en cuenta también la de la dueña de casa"7.

La conclusión no puede ser otra: los mundos liberales escindidos de la vida privada y la vida pública están interrelacionados, conectados por una estructura patriarcal injusta. Si las teorías de la justicia quieren hacer bien su trabajo, deberían revisar esa distinción. Pateman ha graficado muy bien esta relación en lo que ha llamado el dilema Wollstonecraft que cruza transversalmente cualquier intento de lograr una ciudadanía plena para las mujeres ${ }^{8}$.

6 ZÚNiga Fajuri et al. (2007).

7 Pateman (1996) p. 48.

8 Mary Wollstonecraft postulaba que las mujeres no son inferiores a los hombres por naturaleza, sino por la educación que reciben. Adelantándose a la distinción sexo-género, defendió que esa educación degradada contribuye a que las mujeres no sean miembros útiles para la sociedad, aunque compartan con los hombres lo que 
Dicha disyuntiva ilustra el atolladero entre dos demandas en principio incompatibles: por una parte, reclamar igual ciudadanía dentro del actual marco androcéntrico y, por otra, destacar que las capacidades específicas, las aptitudes y las necesidades de las mujeres deben ser reconocidas en la esfera pública. Las dos alternativas son aparentemente excluyentes puesto que las mujeres o deben adaptarse a lo que no son -varones- para poder actuar como ciudadanas plenas, o deben persistir en que se les reconozcan sus aportes al bienestar general mediante sus tradicionales roles de cuidado en el ámbito doméstico y de transferencia de poder y trabajo no reconocido hacia los hombres, los que precisamente no tienen peso a la hora de definir la ciudadanía. Cómo se resuelva ese dilema será crucial para construir un modelo institucional no opresivo.

\section{LA MUJER DE LAS SOCIEDADES LIBERALES: ¿EXPLOTADA E INVISIBLE?}

La sociedad democrática liberal en la que vivimos es también opresiva. Una de las corrientes del feminismo -que suele llamarse socialista- nos da muy buenas razones para admitirlo. Según Young, la principal razón por la que pocas personas usarían el término opresión para referirse a las injusticias en las sociedades democráticas contemporáneas, es que comprenden la expresión de forma tradicional, esto es, como el ejercicio de un poder tiránico por parte del grupo gobernante. Pero ella propone un nuevo concepto. La "opresión designa las desventajas e injusticias que sufre alguna gente no porque un poder tiránico la coaccione, sino por las prácticas cotidianas de una bien intencionada sociedad liberal (...) la tiranía de un grupo gobernante sobre otro grupo social (...) sin duda debe señalarse como opresiva. Pero la opresión se refiere también a los impedimentos sistemáticos que sufren algunos grupos y que no necesariamente son el resultado de las intenciones de un tirano. La opresión así entendida es estructural y no tanto el resultado de las elecciones o políticas de unas pocas personas" .

Ese poder, presente todavía en nuestras decentes democracias constitucionales, se expresa a través de la explotación, esto es, un proceso sostenido de transferencia de los resultados del trabajo de un grupo social en beneficio de otro. Un ejemplo paradigmático de explotación es aquella que se sustenta en la categoría de la "clase", pero otro muy significativo es la explotación de género. "No ha sido difícil para las feministas demostrar que la opresión de las mujeres consiste, en parte, en una transferencia, sistemática y no recíproca de poderes de las mujeres a los hombres". Baste reconocer que ellos pueden funcionar con relativa tranquilidad en el espacio público gracias a que ellas trabajan para ellos en la esfera privada. Todas las penosas y cansadoras tareas domésticas sin las cuales, claro está, no podríamos desempeñarnos en el espacio público -cocinar, lavar, limpiar, cuidar a niños y ancianos- son realizadas por mujeres. Ello significa, en términos económicos, que ellas transfieren a los hombres su fuerza de trabajo -casi siempre de manera gratuita- liberándolos del costo en tiempo y dinero que les significaría a ellos realizar esas tareas imprescindibles para moverse en la vida laboral.

es propio del ser humano: la razón. Pateman (1989) pp. 195-204.

9 Young (2000) pp. 74-75. 
Así, la opresión de las mujeres no consiste meramente en una desigualdad de estatus, poder y riqueza resultante de la práctica por la cual los hombres han excluido a las mujeres de las actividades privilegiadas. La libertad, poder, estatus y autorrealización de los hombres es posible precisamente porque las mujeres trabajan para ellos. La explotación de género tiene dos aspectos: la transferencia a los hombres de los frutos del trabajo material y la transferencia a los hombres de las energías sexuales y de crianza" ${ }^{10}$.

Para superar esa explotación de género se requiere algo más que la redistribución de bienes. Mientras no se modifiquen las prácticas institucionalizadas y las relaciones estructurales, los procesos de transferencia volverán a crear una desigual distribución de recursos con el paso del tiempo. Hacer justicia donde existe explotación demanda, al menos, reorganizar las instituciones y las prácticas de toma de decisiones, modificando la forma en que se divide el trabajo entre los sexos.

Pero, como vimos, las mujeres, además de ser explotadas en el sentido explicado, son marginadas, pues se encuentran excluidas de la participación en las principales actividades sociales. Carecen de poder ya que viven y trabajan bajo la autoridad de otras personas, lo que les impide gozar de ese bien incorpóreo tan relevante en el mundo capitalista llamado "respetabilidad", es decir, esos privilegios de quienes desempeñan roles reverenciados y valorados en la sociedad como podría ser un médico, un ingeniero, un economista, un abogado, pero nunca una cuidadora de niños o ancianos, por muy relevante que ello sea para el funcionamiento de la sociedad. Los privilegios de la respetabilidad profesional aparecen con claridad en la dinámica del sexismo: en el trato cotidiano las mujeres deben probar y luchar por su respetabilidad y, muchas veces, pagar por ella.

Baste recordar cómo fue necesario introducir "audiciones ciegas" en la mayoría de las orquestas durante las décadas de los 70 y 80 ante la alarmante falta de mujeres. Los directores, junto con los restantes miembros del comité de selección, comenzaron a escuchar a los candidatos separados por una cortina, sin conocer su identidad. Al principio se hacían 3 rondas de audiciones con los mismos músicos. En la primera ronda los responsables de la selección podían ver a los candidatos aunque no podían intercambiar palabra con ellos. Simplemente tocaban la pieza seleccionada delante de ellos. El resultado fue que la mayor parte de los músicos seleccionados fueron hombres. En la segunda ronda, los responsables de la selección no podían ver a los músicos ya que tenían por delante un biombo. Es decir, la audición se realizaba a ciegas. El resultado de nuevo fue que la mayor parte de los seleccionados fueron hombres ¿qué ocurría?

En la última ronda, la audición se realizó en las mismas condiciones que la segunda ronda pero con un matiz: los candidatos estaban descalzos. El resultado fue que la mayor parte de los candidatos seleccionados fueron mujeres. La razón de esto fue que en la segunda ronda los responsables de las audiciones sabían si el candidato era hombre o mujer por el sonido de los tacones.

Otro ejemplo más reciente de invisibilidad y discriminación se muestra en un estudio del año 2003 en el que los profesores Flynn y Anderson, de la Universidad de Nueva York y Columbia, respectivamente, llevan a cabo un experimento para poner a prueba las

10 Young (2000) p. 89. 
percepciones de los hombres y las mujeres en el lugar de trabajo. Comenzaron con el estudio de un caso real en la facultad de ciencias empresariales de Harvard sobre una empresaria llamada Heidi Roizen. El caso describía cómo Roizen llegó a ser una inversora de éxito empleando su "personalidad extrovertida (...) y una vasta red personal y profesional que incluía a muchos de los líderes empresariales más poderosos del sector de la tecnología”"11.

Flynn y Anderson asignaron a la mitad de los estudiantes la lectura de la historia de Heidi y entregaron a la otra mitad de los estudiantes la misma historia profesional, pero con un pequeño detalle de diferencia: esta vez "Heidi" se llamaría "Howard". Una mujer y un hombre con idénticas vidas laborales. De nuevo, el resultado fue demoledor para las mujeres. Los alumnos a quienes les tocó la identidad de Howard, lo encontraron eficiente, inteligente, fuerte, decidido y exitoso. Un tipo admirable e inspirador en todos los sentidos. Quienes comentaron la personalidad de Heidi dijeron que era igualmente eficiente y exitosa. Pero les inspiraba antipatía: para ellos, era agresiva, egoísta, personalista, desagradable y, probablemente, sin sentido del trabajo en equipo. "Una escaladora"12.

La explotación e invisibilidad en la que vive la mujer occidental tiene su expresión más fuerte, no hay duda, en la violencia: las mujeres están expuestas a la violencia no solo como el resultado de las acciones individuales moral y jurídicamente reprochables, sino también como consecuencia de prácticas sociales sistemáticas que se dirigen en contra de ellas simplemente por el hecho de ser mujeres ${ }^{13}$. Además, son víctimas de un cierto imperialismo cultural pues son juzgadas conforme a estereotipos que les arrebatan su individualidad. Así como cualquiera sabe, plantea Young, "que el sol sale por el oriente, cualquiera sabe que los homosexuales son promiscuos, los indígenas son alcohólicos, los pobres flojos, y las mujeres las más aptas para el cuidado de niños y ancianos. En cambio, los hombres blancos pueden ser individuos al no estar esencializados por estereotipos de grupo. La injusticia del imperialismo cultural radica en que "las experiencias e interpretaciones de la vida social propias de los grupos oprimidos cuentan con pocas expresiones que afecten a la cultura dominante, mientras que esa misma cultura impone a los grupos oprimidos su experiencia e interpretación de la vida social"14.

\section{EL CAMINO HACIA UNA SOCIEDAD DE IGUALES}

La opresión estructural que sufren las mujeres, que les niega su calidad de agentes morales iguales a los hombres, es la causa más profunda de su marginación y pobreza. Mientras esa opresión subyacente, instalada en el corazón mismo de las sociedades en las que vivimos, no se modifique, no habrá cambios en las cifras ${ }^{15}$. La violencia se vincula directamente con la falta de independencia económica y moral de las mujeres, quienes suelen realizar los trabajos peor remunerados o valorados socialmente.

\footnotetext{
11 Toegel y Barsoux (2012).

12 Otros casos similares son Moss-Racusin, C.A., Dovidio, J.F., Brescoll, V.L., Graham, M.J. \& HandelsMAN, J. "Science faculty's subtle gender biases favor male students". PNAS, Vol. 109 № 41.

13 Valenzuela y Zúñiga Fajuri (2014).

14 Young (2000) p. 105.

15 Palacios (2013).
} 
Pero no todo está perdido. Existen países que se han tomado seriamente la problemática de la discriminación contra la mujer asumiendo que la clave del cambio radica en terminar con la explotación y, por tanto, apostar decididamente por la división equitativa de los roles sociales tanto en el espacio público como privado.

Moss propone una división de estos países en tres grupos: Primero, países con estados de bienestar que proveen un conjunto de licencias parentales remuneradas durante un periodo de al menos nueve meses, manteniendo los ingresos salariales (2/3 o más del salario). En este grupo se encuentran los cinco países nórdicos (Islandia, Finlandia, Dinamarca, Noruega y Suecia), tres países del Centro y del Este de Europa (Eslovenia, Estonia y Hungría) y Alemania ${ }^{16}$.

En segundo lugar están aquellos países que permiten entre cuatro y seis meses de licencia retribuida (al menos con 2/3 del salario) a las madres mayoritariamente y, en algunos casos, a los padres. Como no se trata del tipo de licencia parental con sostenimiento de los ingresos salariales, es inasequible para la mayoría de madres y padres trabajadores. España se encuentra en este grupo. Finalmente, se hallan los países que proveen menos de dos meses de licencias remuneradas (2/3 del salario previo), entre los que están los cuatro principales países de habla inglesa, Australia, Canadá, Estados Unidos y Reino Unido ${ }^{17}$. Con todo, el estado de Québec dentro de Canadá (de orientación socialdemócrata)ha desarrollado desde 2006 una política propia de licencias parentales, que lo sitúa en el primer grupo de países; el resto de Canadá ofrece hasta 50 semanas de licencia remunerada, pero con la mitad de los ingresos salariales previos, por lo que está debajo del indicador de la Comisión Europea ${ }^{18}$.

Se ha comprobado que cuando la licencia parental es solo un derecho, su uso por parte de los varones es bajo. Por ejemplo, un 2\% en Finlandia o Polonia, 3\% en Austria, 5\% en Alemania -con la regulación anterior a 2007- y un $10 \%$ en Canadá ${ }^{19}$. Pero si la licencia parental es concebida como un derecho individual intransferible y es bien remunerada, el uso entre los hombres aumenta. En este caso están los países nórdicos, como Dinamarca, donde el 62\% de los hombres con hijos nacidos entre 2002/03 usó la licencia parental una media de 25 días. En Islandia, en el año 2003 por cada 100 madres, 84 padres usaron algún periodo de licencia parental, una media de 94 días. En Noruega, un 89 \% de los padres en 2003 usaron la licencia parental, aunque solo el $15 \%$ la usó más tiempo que el mes de cuota paterna intransferible. Finalmente en Suecia el 90 \% de los padres de hijos nacidos en 1998 han usado la licencia parental, principalmente cuando sus hijos tenían entre 13 y 15 meses de edad ${ }^{20}$.

Estas cifras evidencian que, si bien el cuidado de los hijos continúa siendo un elemento asociado al género, es posible incentivar un cambio gradual que reparta la responsabilidad paterna desde el trabajo remunerado hacia la atención y el cuidado de los hijos. Es decir, hacia la promoción eficientemente de la igualdad.

\footnotetext{
16 Moss (2007).

17 Moss (2007).

18 Escobedo (2008).

19 Moss (2007).

20 Escobedo (2008).
} 


\section{CONCLUSIÓN: HACIA UNA IDEA COMPLEJA DE IGUALDAD}

El derecho a la igualdad consiste en ser tratado con la misma consideración y respeto. Su justificación se deriva directamente de la atribución a todos los seres humanos de la idéntica calidad de agentes morales ${ }^{21}$. Este ideal nos exige la remoción de cualquier obstáculo que niegue esa tratamiento, lo que suele denominarse igualdad formal. Tal sería el caso de postulados racistas, sexistas o discriminadores en razón del género ${ }^{22}$. Pareciera evidente que la igualdad entendida en estos términos es una exigencia de la racionalidad ética, que se deriva de la universalización de la dignidad última que cada uno de nosotros se atribuye como agente moral y que, por ello, hemos de reconocernos recíprocamente entre todos los agentes morales.

Pero vistas así las cosas, la igualdad es, todavía, un principio modesto, puesto que si bien nos sirve para negar cualquier discriminación en el igual acceso a las libertades individuales, es inútil si no va acompañada de la satisfacción de las necesidades suficientes para poder ser libres realmente. La defensa de las libertades solo tiene sentido en cuanto se corrijan materialmente las desigualdades que impiden que cada persona se trace para así autónomamente su proyecto de vida. Con lo anterior queremos enfatizar que cualquier teoría de la justicia mínimamente igualitarista debe ocuparse de una redistribución desigual de los recursos básicos para asegurar que todas y cada una de las personas gocen de las posibilidades fácticas que les permitan ser libres. De este modo, la igualdad material -como complemento indispensable de la igualdad formal- se refiere a la necesidad de dotar a todas a las personas, de conformidad a sus capacidades, de alimentos, sanidad, condiciones de vida, educación, información y capacitación para ejercer la propia autonomía en similares condiciones de partida que los demás.

Así, el ideal de igualdad es la igualdad entre todos los seres humanos en los recursos adecuados para satisfacer las necesidades básicas, de forma que permitan a todos y cada uno desarrollar de forma equiparablemente autónoma y libre su propio plan de vida. Probablemente alrededor de la distinción entre la igualdad formal y material como así también los diferentes modelos que se han ideado de justicia distributiva, se producen algunas de las más importantes disputas sobre la igualdad ${ }^{23}$.

Sin embargo, aún queda otro ámbito por explorar: la igualdad de reconocimiento. Esta dimensión es especialmente relevante para remover obstáculos estructurales como los que han facilitado y consolidado la opresión de las mujeres en sociedades como las democracias constitucionales modernas que han avanzado decididamente, aunque con diferentes énfasis, en la dimensión formal y material de la igualdad. La omisión sistemática de la igualdad de reconocimiento se funda en el error muy extendido de que el principio de igualdad se vincula exclusivamente con la justificación de la redistribución de recursos económicos.

\footnotetext{
21 Laporta (1985).

22 Singer (1995).

23 Ruiz Miguel (2002).
} 
Al interior de los Estados modernos conviven dos tipos principales de jerarquías: la económica y la asociada al estatus ${ }^{24}$. La posición que una persona ocupa en la jerarquía económica está determinada por su relación con el mercado y los medios de producción. La lucha contra las iniquidades inherentes a esta jerarquía genera las políticas de redistribución. La jerarquía del estatus se refleja en una historia de reglas discriminatorias contra grupos de menor categoría, y su invisibilidad o carácter estereotipado en comparación con el "ciudadano normal". La lucha contra estas jerarquías genera las políticas de reconocimiento o de la diferencia.

La evidencia sugiere que la jerarquía del estatus no es reducible a la jerarquía económica. Es decir, en nombre de la igualdad lo que habrá de redistribuirse no siempre son recursos económicos, sino también, en muchos casos, recursos simbólicos. Probablemente un muy buen ejemplo pueden ser los casos de grupos económicamente bien posicionados, pero culturalmente estigmatizados, como los homosexuales, ciertos inmigrantes y algunas grupos religiosos minoritarios ${ }^{25}$.

Las mujeres demandan, entonces, como grupo oprimido no solo un decidido ataque a las desigualdades generadas por una injusta distribución de los recursos (no olvidemos que el $70 \%$ de los pobres del mundo son mujeres), sino también una remoción de los obstáculos que les impiden tener un igual reconocimiento de su identidad e individualidad en condiciones equivalentes a los varones. Mientras ello no suceda, las causas profundas -arraigadas en el patriarcado y el contrato sexual a través del cual las mujeres transfieren poder, energía y tiempo a los hombres- se mantendrán inalterables, la violencia contra ellas seguirá siendo justificada, explicada o minimizada y la relación con sus cuerpos culpabilizada y reprimida. Es nuestro deber perentorio, y como tal ineludible, contribuir a que el tiempo de los derechos se cristalice también para las mujeres.

\section{BIBLIOGRAFÍA CITADA}

Amnistía Internacional (2009): La trampa del género. Mujeres, Violencia y Pobreza (Madrid, Editorial Amnistía Internacional).

Casas, Lidia, Riveros, Francisca y Vargas, Macarena (2012): Violencia de género y la administración de justicia (Santiago, Servicio Nacional de la Mujer).

Delanty, Gerard (2010): Community (Londres, Routledge, segunda edición).

Escobedo, Anna (2008): "Políticas de licencias parentales y de atención infantil para los menores de tres años y sus familias: el caso español en el contexto internacional”, en PAzos, María (dir.), Economía e igualdad de género: retos de la Hacienda Pública en el siglo XXI (Madrid, Instituto de Estudios Fiscales) pp. 161-183.

Fraser, Nancy (2010): “Rethinking Recognition”, New Left Review, 3: pp. 107-120. Hierro, Liborio (2002): "El concepto de justicia y la teoría de los derechos", en Díaz, Elías y Colomer, José Luis (edit.), Estado, justicia, derechos (Madrid, Alianza) pp. 11-73. JaCKSON, Jennifer (2005): Minority Rights (Londres, Polity Press).

24 Fraser (2010).

25 Kymlicka (2002). 
Kymlicka, Will (2002): Contemporary Political Philosophy. An Introduction (Londres, Oxford University Press, segunda edición).

LAPORTA, Francisco (1985): "El Principio de Igualdad: Introducción a su Análisis", Sistema, N 67: pp. 3-31.

Laporta, Francisco (1987): "Sobre el concepto de derechos humanos", Doxa, № 4: pp. 23-46.

Modood, Tariq (2007): Multiculturalism. A Civic Idea (Cambridge, Polity Press).

Moss, Peter. (2007): “Introduction to country notes", en Moss Peter y Wall, Karin (edit.), International Review of Leave Policies and Related Research 2007 (Londres, Department of trade and Industry) pp. 45-71.

Nino, Carlos (1989): Ética y Derechos Humanos (Buenos Aires, Astrea).

Palacios, Patricia (2013): "La violencia en contra de las mujeres", en Lacrampette, Nicole (edit.), Derechos Humanos y Mujeres: Teoría y Práctica (Santiago, Centro de Derechos Humanos, Universidad de Chile) pp. 277-336.

Pateman, Carole (1989): The Disorder of Women: Democracy, Feminism, and Political Theory (California, Stanford University Press).

Pateman, Carole (1996): "Críticas feministas a la dicotomía público/privado", en CASTElls, Carme (comp.), Perspectivas feministas en teoría politica (trad. Carmen Castells, Barcelona, Paidós) pp. 2-23.

Ruiz Miguel, Alfonso (2002): “Concepciones de la Igualdad y Justicia Distributiva”, en Díaz, Elías y Colomer, José Luis (edit.), Estado, justicia, derechos (Madrid, Alianza) pp. 211-242.

SÁnchez, Cristina (2002): "Feminismo y ciudadanía”, en DíAz, Elías y Colomer, José Luis (edit.), Estado, justicia, derechos (Madrid, Alianza) pp. 347-370.

Singer, Peter (1995): Ética Práctica (trad. Rafael Herrera Bonet, Cambridge: Cambridge University Press).

Squella, Agustín, Villavicencio, Luis y Zúniga Fajuri, Alejandra (2012): Curso de filosofía del derecho (Santiago, Editorial Jurídica de Chile).

Toegel, Ginka y Barsoux, Jean-Louis (2012): "Women Leaders: The Gender Trap", The European Business Review. Disponible en: http://www.europeanbusinessreview. com/?p=2482. Fecha de consulta: 5 de mayo de 2015.

Villavicencio, Luis (2013): “¿Es política la justicia como equidad?”, Ideas y Valores, vol. 62, No 152: pp. 225-247.

Villavicencio, Luis (2014): "Minorías étnico-culturales y derechos de las mujeres", Revista de Ciencia Política, vol. 34, No 3: pp. 605-621.

Young, Iris Marion (2000): La justicia y la politica de la diferencia (trad. Silvina Álvarez, Madrid, Cátedra).

Zúñiga Fajuri, Alejandra; Aguilera Bertucci, Daniela y Vásquez Bravo, Andrea (2007): "Lejos del poder. Hacia la implementación de una ley de cuotas en Chile", Revista de derecho (Valdivia), vol. 20, No 2: pp. 9-30.

Zúñiga Fajuri, Alejandra y Valenzuela, Cecilia (2014): "Leyes de cuotas electorales, Constitución y democracia”, Revista de derecho (Valdivia), vol. 27, Nº 1: pp. 191-211. 